\title{
Predation in bird populations
}

\section{Will Cresswell}

School of Biology, University of St. Andrews, Fife, KY16 9TS, UK

wrlc@st-and.ac.uk

Key words: trait-mediated indirect effects; compensatory mortality; doomed surplus; lethal effects; non-lethal effects; non-consumptive effects 


\section{Abstract}

One of the classic ecological questions is how predators affect population size. This is often assessed by measuring how many individuals are killed by a predator, yet such direct effects may only be a relatively minor part of population dynamics. Predators frequently affect prey populations indirectly, with the fear of predation resulting in costly behavioural compensation leading to potentially large population and community effects. Large observable lethal effects may then just represent the most easily observed "special" cases of the effects of predation on populations, with the costs of non-lethal effects being ubiquitous and usually dominant. This review explores these two ideas: that cases where there are no population effects due to predation, and cases where lethal effects dominate, are unusual and involve special circumstances. First, systems where predation effects appear not to arise include complete avoidance of predators by prey; when other environmental factors limit populations so that predation is not additive to mortality; when there are other more vulnerable prey for a predator; when predators interact; because the relationship of perceived predation risk with predator abundance is usually a non-linear function, and simply because non-lethal effects have not been considered. Second, lethal effects tend to dominate over non-lethal effects when there is a high cost of compensating for predation risk associated with either resource constraint or a particularly vulnerable niche or life history stage (e.g. the nest stage generally for birds); when prey are the most popular prey of a predator or linear trophic chains operate; when there is evolutionary lag such as introduced predators and naïve prey populations; and when there are several predator species hunting the same prey in diverse ways. The presence of predators may or may not affect the size of a bird population at any particular life history stage, although in most cases it will through non-lethal effects and occasionally through lethal effects. But the presence of predators will always affect intra- and interspecific competition and so will always affect population dynamics. Studies that wish to fully demonstrate that predation has no effect on bird populations must show that lethal effects and the costs of non-lethal compensation by the prey do not significantly change its density and so the level of competition. 


\section{Introduction}

One of the classic ecological questions is how predators affect the size of prey populations (e.g. Lack 1954). Bird populations have been extensively studied to answer this question both from a theoretical point of view and from an applied management or conservation point of view (Martin 1991; Newton 1993; Newton 1998). The answer to the question is, as with most things ecological, context and case specific (e.g. see Newson et al. 2010). Some studies have concluded that predators are important in determining the size of bird populations, where increasing predator numbers result in lower prey populations (e.g. Tharme et al. 2001; Smith et al. 2010; Fletcher et al. 2010). But others have shown that predator numbers or predator presence do not change prey numbers (e.g. Bolton et al. 2007; Holt et al. 2008; Amar et al. 2010). Almost all of the emphasis in these published studies is on measuring how many individuals are directly killed by a predator: if some proportion of the prey population is killed by a predator, or prey population declines are recorded because of the predator killing prey, then a predator is regarded as being important in influencing the prey's population dynamics (Holt et al. 2008; Smith et al. 2010). Yet predators actually killing prey may often be only a minor part of the effect of predation in populations (Brown et al. 1999; Sih 1987; Creel and Christianson 2008; see Cresswell 2008 for a review of this idea).

Predators frequently affect prey populations indirectly, with the fear of predation resulting in large individual fitness decreases and potentially large population and community effects (Abrams 1984; Abrams 1991). These can result even with no prey actually being killed by a predator. There may then be only a weak relationship between numbers of predators and prey population, or with the number of prey directly killed by predators (Abrams 1993). The relative strength of non-lethal effects, their predominance in determining population and community effects, and the decoupling of number of prey killed and predator abundance from the strength of these effects is very well established in the ecological literature (Lima 1998; Agrawal 2001; Bolker et al. 2003; Krivan and Schmitz 2004; Schmitz et al. 2004; Preisser et al. 2005). 
If we consider non-lethal effects as inevitable whenever one species hunts another that is capable of behaviours that might reduce its risk of attack or capture, then there should only ever be special circumstances when predators do not affect prey populations indirectly. Widespread non-lethal compensation then makes lethal effects less likely, so that population size changes as a result of direct predation may well be relatively uncommon. But population changes through direct mortality are usually more obvious than non-lethal effects, making them relatively easy to describe and publish, so giving a biased idea of the population and community effects typically exerted by predators. This review explores these two ideas: that cases where there are no population effects due to predation, and cases where lethal effects dominate, are unusual and involve special circumstances. In this review I discuss:

1. How non-lethal effects might dominate in bird populations and so how this leads to the conclusion that predation always affects bird population dynamics, regardless of whether population changes are observed.

2. The conditions which lead to the apparent weakening of non-lethal effects. These include complete avoidance of predators by prey; when other environmental factors limit populations so that predation is not additive to mortality; when there are other prey species more vulnerable; when predators interact; because the relationship of perceived predation risk with predator abundance is usually a non-linear function, and simply because non-lethal effects have not been considered.

3. The conditions which lead to the apparent strengthening of lethal effects relative to nonlethal effects. These include when there is a high cost of compensating for predation risk associated with either resource constraint or a particularly vulnerable niche or life history stage (e.g. the nest stage generally for birds); when prey are the most popular prey of a predator or linear trophic chains operate; when there is evolutionary lag such as introduced predators and naïve prey populations; and when there are several predator species hunting the same prey in diverse ways. 
4. The question of whether there really are cases where predators and prey coexist without significant population changes on any spatial or temporal scale, and so whether "compensatory" mortality is anything more than a consequence of examining the population changes caused by predators on a limited scale and without considering the non-lethal effects of predation risk on intra-specific competition.

\section{Non-lethal effects and the subtle population effects of predators}

Animals always pay a cost to reduce predation risk when they can (Brown et al. 1999; Brown and Kotler 2004). Costs arise from behaviours that enhance short term survival in the presence of the predator, but that decrease long term fitness, such as body condition or reproductive potential (see Preisser et al. 2005). A good example of this is the starvationpredation risk trade-off (Abrams 1984; McNamara and Houston 1987). Animals often avoid areas that would give them the highest intake rate, instead they choose areas which have lower predation risk (Houston et al. 1993). Nor do they forage in ways that maximise intake rate, instead they allocate potential foraging time to anti-predation behaviours such as vigilance (McNamara et al. 1994). The cost that such choices entail can be measured by determining the decrease in overall intake rate compared to that if the animal fed in the most profitable area at its maximal rate (Lima 1986; Houston et al. 1993). Alternatively the costs that animals are prepared to bear to reduce predation risk can be assessed by "titration" experiments, where the profitability of a safe site is reduced to a sufficiently low level that the animal starts feeding in the risky area or in a more risky way (Kotler and Blaustein 1995). Chaffinches Fringilla coelebs, for example, will only start to feed for any time in a habitat that obscures their view of approaching predators when their foraging gain in good visibility habitat becomes very low (Butler et al. 2005).

Any fitness reductions and their population consequences, as animals minimise short term predation risk, are known as non-lethal effects, non-consumptive effects or trait-mediated interactions (Preisser et al. 2005; Luttbeg and Kerby 2005; Cresswell 2008; Preisser et al. 2009). Non-lethal effects are perhaps most easily understood by considering the example of 
where prey avoid predators. Animals usually occupy "non-lethal space" - patches where predation risk is as low as possible - as long as other aspects of fitness such as body condition or reproductive potential can be maintained. In the Chaffinch example above, the non-lethal space was the high visibility habitat, occupied at a substantial potential foraging cost (Butler et al. 2005). However, when other aspects of fitness can no longer be maintained in non-lethal space animals must then move into "lethal space" - patches where predation risk is higher. Animals start to select more risky but more profitable areas, or more risky foraging behaviours, as their starvation risk increases (Milinski and Heller 1978; Sih 1980; Sih 1982). For example, juvenile Redshanks Tringa totanus may avoid 26\% (Cresswell et al. 2010) and adults 100\% (Cresswell 1994) of the most profitable habitat to avoid attacks by Sparrowhawks Accipiter nisus, unless severe-weather-induced starvation risk forces them to feed in risky areas (Yasue et al. 2003; Cresswell and Whitfield 2008). The concept is illustrated in Fig. 1.

In general terms, the use of lethal space and so the proportion of a population killed directly by predators, depends on the level of investment in anti-predation behaviours. This investment depends on the costs of these anti-predation behaviours and so often on the overall level of resources to offset these costs (Fig. 2). An interaction then arises between resource levels and the effects of predators on populations (Bolnick and Preisser 2005; Preisser et al. 2009). Use of non-lethal space will increase if resources decrease below a threshold, and then predation levels will depend on resource abundance. In contrast, where resources are sufficient so that none of the population is forced into non-lethal space, predation levels will be independent of further increases in resource levels (Fig. 3; see Krebs et al. 1995; Zanette et al. 2003; Zanette et al. 2006 for good empirical examples of this).

Although most of the discussion so far has involved examples of the starvation-predation risk trade-off, birds will, of course, forgo many other long term fitness benefits in addition to foraging gain to minimise short term predation risk. These might include use of safer singing, display, nesting, preening or roosting sites that involve increased costs in terms of utility, travel time and thermoregulation. For example, Swifts Apus apus probably escape nocturnal predation entirely by roosting on the wing (Lack 1956; Backman and Alerstam 2001), and 
Dunlins Calidris alpina may spend several hours aloft to avoid predation by Peregrines Falco peregrinus at high tide (Dekker 1998). In general, if resources are abundant so that the costs of anti-predation behaviour can be met then predation risk is unlikely to manifest itself in terms of prey being directly killed by predators (Luttbeg et al. 2003; Bolnick and Preisser 2005; Preisser et al. 2009).

Overall, applying the theoretical framework that long-term fitness is always traded off against short minimisation of predation risk, whenever possible, leads to the logical conclusion that predation must always affect bird populations, and so is likely to also always affect population dynamics. This is supported by a large body of evidence to show that non-lethal effects lead to population consequences. There are hundreds of case studies, and several reviews of these, that show that predators exert significant non-lethal population effects on their prey (Cresswell 2008). These reviews show that non-lethal effects usually have at least the same effects on prey populations as direct predation effects. When community effects are considered (i.e. effects that accrue across trophic levels because of altered prey behaviour, distribution and competition), then $85 \%$ of all effects of predators may arise non-lethally (Preisser et al. 2005).

\section{Under what circumstances do we apparently not find any predation effects?}

Although theoretically, if predators hunt a prey species, we should always expect non-lethal effects on fitness, it is possible that there may be some circumstances where these fitness changes do not have significant population consequences. Certainly there are many case studies where changes in predator numbers have apparently little effect on bird populations (Newton 1998; Holt et al. 2008). Some of these may represent special circumstances when predation genuinely has little effects on population, and include when prey have actually permanently escaped direct predation; when other factors limit the size of the breeding population; and when a prey is particularly vulnerable so potentially shielding other prey from high anti-predation costs. Others may simply represent methodological failures to properly account for non-lethal effects. 
When discussing any evidence of direct limitation or not of prey numbers by predators, it is important, to explicitly define the temporal stage of predation (Newton 1998). Predators may exert a direct control of post-breeding populations because eggs, chicks and newly fledged juveniles lack behavioural-compensation, yet may have little effect on adult mortality and so breeding numbers the following year. The absolute direct lethal effects and the relative effects of lethal versus non-lethal predation will therefore often be dependent on the life history stage being considered (e.g. see Cresswell and Whitfield 2008).

\section{When predation is genuinely absent}

Landscapes are heterogenous and predators have limitations, so there are areas and times when predation risk can be escaped (Heithaus et al. 2009). Permanent escape from predation risk without cost is possible, but is a special case where the absence of predators on islands (as discussed below) has led to loss of costly anti-predation behaviour, and indeed occasionally the physical ability to compensate non-lethally for predation risk. Apparent or temporary escape from predation risk can also be achieved by temporary use of habitats or areas that are predator free. If predators are at low density and suitable habitat abundant then prey species can play a successful game of hide-and-seek with predators (Wirsing et al. 2010). This may be an important component of the strategies of migrant bird species that use high latitude areas. But migration is a costly strategy and so there are likely to be non-lethal effects operating at the level of life-history selection (see Schmidt-Wellenburg et al. 2008). For example, higher adult or nestling survival may be traded off against reduced annual reproductive output (Dobson and Power 1990).

It is important to make the point that escape from predation does not mean that predation risk is not exerting fitness and population level consequences through non-lethal effects. Any escape into "non-lethal space" will lead to increased competition (e.g. Leibold 1991) because the best individuals will occupy the least risky patches to capacity preferentially (Grand 2002). Another important point to make is that apparent complete escape from predation risk may lead to "cryptic" non-lethal costs, and indeed a failure to appreciate any predation effects at all. 
If all of a population has avoided a predator successfully, then there will be no observed lethal effects, and there will be no comparative fitness measures from individuals that are exposing themselves to predators from which to gain an assessment of non-lethal costs. But, environmental heterogeneity and anthropogenic change, whether through deliberate experiment or inadvertent reduction in levels of resources, may elucidate these costs because there will be few situations where all of the population can afford to avoid risky situations, all of the time.

\section{When predation is relatively weak or compensatory}

Long term population effects of predation may not be seen, even with apparently high levels of direct mortality, or large non-lethal effects. This is because mortality can be partitioned into a section of the population that has negligible fitness anyway (Lack 1954). A classic example of this is the long term studies of both Great Parus major and Blue Tit Cyanistes caeruleus populations at Wytham Wood, Oxford. Populations here remained constant over several decades regardless of the presence or absence of Sparrowhawks, which eat large numbers of tits, and cause large changes in their behaviour (Newton 1998; Perrins and Geer 1980). First winter tits, and in particular, newly fledged birds have a low chance of survival regardless of predation because they compete with adults, and this density dependent competition and subsequent mortality will increase if fewer tits are killed by Sparrowhawks. A further density dependent effect operates through competition for breeding territories and nest holes, so that even if overwinter survival is enhanced overall in the absence of Sparrowhawks, many of the survivors fail to breed successfully. Put simply, predators may have no effect on prey populations if the same number of prey that are killed by predators would otherwise have died or not reproduced anyway - i.e. a "doomed surplus". This type of mortality from predators that does not add to the overall number of animals dying is known as compensatory mortality (Errington 1945). It implies limitation of breeding numbers by a factor other than direct predation, but it does not rule out population effects of predation at all temporal and spatial scales. Despite compensatory mortality by predators, by definition, not affecting overall breeding population numbers, predation risk is always likely to affect resource availability, and 
so intraspecific competition for resources via non-lethal effects, and so is likely to have some population level effects (Boyce et al. 1999).

This is shown by the tit example above, where there are strong lethal effects during the winter because competition between first winter birds and adults pushes young birds into lethal space, and adults show strong non-lethal effects as they maintain lower fat reserves and face competition as they forage in the safest areas (Gosler 1996). Even if the proportion of the population that is killed by predators represents a "doomed surplus", the proportion of the population that survives will have paid a fitness cost to be the survivors. Similarly, although the breeding population of tits may be limited by availability of nest sites, the overall population level during the breeding season would be higher if predators were removed (because some birds would then escape density dependent mortality by exploiting what was formerly lethal space). These "surplus" birds would then disperse and so affect population dynamics elsewhere. Alternatively, these survivors could form a population of non-breeding "floaters" affecting reproductive output of those breeding birds through intraspecific competition and affecting long-term population dynamics should the breeding population suffer increased mortality from non-predation sources (e.g. Jenkins et al. 1964).

True compensatory mortality is also unlikely because of temporal and spatial environmental variation will cause variation in resource levels. This is because predators will always tend to reduce population levels to the size of non-lethal space set by the lowest level of resources during any period, so reducing intra-specific competition when resources become less constrained and non-lethal space becomes larger. Compensatory mortality therefore seems likely to always be associated with changes in intraspecific competition, and such changes are very likely to have population consequences (Chase et al. 2002).

\section{When less preferred prey have lower costs to reduce vulnerability}

Some species, or part of a species' population, will always be inherently less vulnerable (e.g. Errington 1943; Selas 1993; Tornberg 1997; Lingle et al. 2005) and so will have lower costs to reducing risk to the same level compared to the more vulnerable species or sub-population. In 
other words, if a species (and individual can be substituted for species throughout here), all things being equal, is less preferred prey, then any anti-predation behaviour will have more effect relative to more preferred prey. Consequently behaviours that equalise vulnerability will be lower cost for the less preferred prey. As costs of behavioural compensation decrease so the likelihood that they will be used increase. Therefore as long as there is a most preferred prey present, then less preferred prey may show little direct predation (e.g. Tschanz et al. 2007) and more importantly may also show relatively little decrease in fitness because of their non-lethal compensation.

Theoretically if a generalist predator such as a Sparrowhawk has a clear rank order of preferred prey and these are abundant, then many prey species low down on the list of preference are unlikely to show any effects of predation on their populations. Wrens Troglydytes troglydytes, for example, are killed by Sparrowhawks at a rate much less than expected from their relative abundance: they typically occupy dense cover, are cryptic and are very low profitability (Tinbergen 1946; Cresswell 1995). Such species may have to invest relatively little in behaviours to reduce risk and so will show small non-lethal effects. Blackbirds Turdus merula, in contrast, are taken by Sparrowhawks much more than expected from their relative abundance: they forage in more open habitats, are conspicuous (at least for males) and are highly profitable (Cresswell 1995; Götmark and Post 1996). Such species will have to invest more in anti-predation behaviours such as vigilance and avoid profitable feeding areas away from protective cover and so will show strong non-lethal effects. Because both species compensate for predation risk, relatively few individuals of either species may actually be killed by Sparrowhawks, but Blackbirds will show much stronger non-lethal effects of Sparrowhawk predation risk on individual behaviour and consequent population size.

Whether this argument means that some species are protected by more vulnerable species, and so have relatively trivial lethal and non-lethal effects of predation risk is questionable. Non-lethal effects operate on a threshold (see below) so that even a very low risk of predation can still result in large non-lethal effects (Abrams 1993). Also a prey species is unlikely to be at risk from a single predator species, its risk will vary dependent on resource availability and 
life history priority, and predators themselves may often attack less preferred prey because preferred prey can become relatively locally invulnerable if the predator is detected (Lima et al. 2003). Nevertheless the basic hypothesis that less preferred prey will have lower costs of compensation for predation risk and so smaller population consequences because of predators seems reasonable. This may apply particularly if predators are limited in a density dependent way so that the presence of a vulnerable prey species does not result in increased predator density for other prey species.

\section{When food webs are diverse and predators interact}

A particular predator species may not appear to affect prey populations, either as a consequence of its removal, or over a range of densities, because other predator species may compensate for its effects (Peckarsky and McIntosh 1998). There are usually a range of avian generalist predators that can potentially eat the same prey species, although at varying efficiencies. Consequently the presence or absence of one predator species may mean that there is little modification in behaviour for a wide range of prey species because other predator species cause the same non-lethal effects (e.g. see Balaz et al. 2007 for how effects can potentially be confounded by multiple predators; Newson et al. 2010).

When predator suites are diverse, as well as interference competition between predators, there may also be predation of the predators themselves, or what is known as intraguild predation (Sergio and Hiraldo 2008). Consequently, if one predator is removed there may then be removal of direct predation effects, or more likely removal of non-lethal compensation on another potential predator (e.g. mesopredator release, see Crooks and Soule 1999). This may result in the released predator species taking over the role of the removed predator in causing lethal and non-lethal effects. From an experimental point of view, the lack of apparent effect of removal of predators on the prey population would be misleading evidence to support the noneffect of the predator on its prey populations unless the complete predator suite had been removed (e.g. Fletcher et al. 2010) or the effects of other potential predator species are considered (Ritchie and Johnson 2009). 
Non-linear and threshold effects of predation risk

The final set of circumstances that may produce the impression that predation does not affect prey populations may simply be because non-lethal effects were not properly appreciated by experimenters or observers of natural variation in ecological systems. The main example of this is where predators are concluded to be unimportant in population regulation, because prey population size does not vary when predator density varies. Such variation may not occur, however, because the relationship between perception of predation risk and behavioural compensation is likely to be non-linear (Abrams 1993). Predation risk will often be a threshold function where even a few predators relative to a large prey population can exert a disproportionally large effect, unrelated to the level of mortality that the few predators can actually exert. This means that predator "removal" experiments that only reduce predator numbers may not actually change perceived predation risk. The same applies to studies that correlate natural variation in predator abundance with prey population changes. For example, it may only take one Peregrine hunting on an estuary for 10,000 Western Sandpipers Calidris mauri, to avoid whole sections of the estuary, or even the estuary entirely (Lank et al. 2003; Ydenberg et al. 2004). If there were 10 Peregrines, for example, the effect would be the same. It might also be expected that anti-predation behaviour may persist in a population long after a predator has disappeared from an area through evolutionary and cultural lag. Both types of studies can also be confounded by compensation by other predator species or mesopredator release as described above.

\section{Under what circumstances do we find strong lethal effects?}

Although theoretically we should usually expect non-lethal effects to dominate, there are many cases where lethal effects have been shown to dominate. These are associated with special conditions where animals are constrained in their ability to compensate behaviourally for predation risk. 
High costs of compensating for predation risk

Strong lethal effects on prey populations might be expected as the costs of anti-predation behaviour rise, or resource levels fall so that animals become constrained in their ability to compensate behaviourally. A classic example of this is small birds in winter (Lima 1986; McNamara et al. 1994). When starvation risk is high during the long, cold nights and short days of winter most small birds put on fat reserves (e.g. MacLeod et al. 2005; Macleod et al. 2008) and adopt foraging areas and tactics that maximise their daily energy intake (e.g. van der Veen 2000; Duriez et al. 2005). In very cold weather birds that normally flee from predators, or perceived predators such as humans, will feed in close proximity to them (e.g. McGowan et al. 2002; Stillman and Goss-Custard 2002). This is because without sufficient fat reserves birds would inevitably starve because foraging is unpredictable and energy costs are high, and in some small species, starvation will occur overnight without fat reserves (Pravosudov et al. 1997). Mortality due to predation is however less certain: predators may have a range of prey individuals to choose from, and if attacked, capture may not occur. Nevertheless direct mortality rates due to predation will increase on average in cold weather, and can lead to substantial population changes (Page and Whitacre 1975; Cresswell and Whitfield 1994).

Strong lethal effects on prey populations might also be expected when birds have different life history priorities. In the temperate winter there are usually only two options available to a bird to maximise fitness: forage and avoid predation. At other times, however, life history stages such as migration (e.g. Inger et al. 2006; Inger et al. 2008), breeding plumage acquisition (e.g. Hagelin 2003), egg production (e.g. Hanssen et al. 2002), incubation (e.g. Cresswell et al. 2004) and moult (e.g. Perez-Tris et al. 2001) may increase the overall fitness costs of reducing foraging intake to minimise predation risk. At such times there may be increased levels of direct predation: we therefore expect stronger lethal effects to be observed in life history stages where the costs of not-maximising intake rate are higher. The same arguments apply for costs associated with resources not directly associated with foraging, such as acquisition of mates, territories, lek positions, song perches, nest sites, preening sites and 
roosting sites. For example, by being restricted to safe nesting sites, birds may avoid predation, but may be limited in distribution with respect to gaining the most resources to produce more offspring (Lima 2009). Individuals or species that cannot nest in a safe site and still produce enough offspring will then show higher levels of direct predation.

One particularly vulnerable life history stage particularly associated with bird populations is the egg and the nestling stage in altricial, semialtricial or semiprecocial species (Lima 2009). Birds gain freedom from hazard by their ability to fly (Pomeroy 1990) and consequently have much longer life expectancy for their size than mammals (Partridge and Barton 1993). This is a reflection of "r" and "K" selection for life history traits, where individuals with low survival must reproduce rapidly and intensively, whereas individuals with higher survival can reproduce more slowly and produce fewer young (Lessells et al. 1991). However, birds cannot move their eggs and so once committed to a nest site, their ability to compensate behaviourally for predation risk by avoidance is limited. Of course nest site selection itself may be a costly nonlethal effect, whether operating at the life history level with species that nest in holes paying costs in terms of restrictions in availability of nest sites or avoidance of parasites, or at the level of individuals deciding to nest in areas far removed from foraging areas to reduce encounters with nest predators (Lima 2009). Nevertheless, once eggs are laid there is much less opportunity for behavioural compensation (Fontaine et al. 2007) and flexibility in behavioural options is a prerequisite for non-lethal effects (Sih and Christensen 2001; Lima 2002; Lima et al. 2003; Cresswell 2008). Therefore, theoretically we expect greater lethal effects in the nest stage than in other stages of bird's life history and so it may be easier to observe population effects when studying nest predation (e.g. see Smith et al. 2010). But it should be noted that many bird species actively defend their nest, often at great perceived risk to the defending bird (e.g. Larsen et al. 1996), or construct their nest at great cost to deter predators (Paclik et al. 2009). Such costs to reduce predation risk on eggs and nestlings are classic non-lethal effects: behaviours that exert a large cost to the nesting bird in time and resources that could otherwise be allocated to other raising more young. 
Most popular prey and simple linear trophic chains

There is considerable inter-specific variation in overall life history strategy that may lead some species to show stronger direct lethal predation effects (Partridge and Harvey 1988). This is simply the "r" and " $K$ " selection argument again. Certain niches will allow escape from predation hazard more readily than others (Partridge and Barton 1993; Bennett and Owens 2002): adult seabirds foraging at very low density may avoid predators completely, whereas adult gamebirds that forage in dense predator concealing cover may not be able to control their frequency of encounters with predators. Therefore, some species of birds, such as Wandering Albatrosses Diomedea exulans and Fulmars Fulmarus glacialis have low rates of reproduction, offset by a very high adult survival rate, and so likely very low predation risk (Lecomte et al. 2010; Dunnet and Ollason 1978). Other species of bird, such as Quails Coturnix coturnix and Corncrakes Crex crex have high rates of reproduction to offset lower nestling and adult survival rates, which also can arise as a consequence of high predation rates, among other factors (Puigcerver et al. 1992; Green et al. 1997).

If some species are more vulnerable than others because, for example, their ecology reduces their ability to avoid predators, or they have a body size most profitable for a foraging predator, then we should expect relatively stronger lethal effects. Most generalist predators have a favoured prey species that maximises ease of capture and body size (Cresswell 1996; Roth et al. 2006). Sparrowhawks, for example, feed on nearly all bird species within their geographic range up to about $500 \mathrm{~g}$, although they favour prey of about $150 \mathrm{~g}$ which are easy to catch (Newton 1986; Cresswell 1995). Although there is geographic variation in which species is taken most frequently (controlling for abundance, i.e. a vulnerability index of greater than 1) a few species, such as House Sparrows Passer domesticus almost always come top of the list of most preferred prey (Tinbergen 1946; Newton 1986; Götmark and Post 1996). A preferred species is, by definition, a more vulnerable species, and so likely to have to pay a greater cost in avoiding predators or adopting behaviours that allow it to reduce its risk of capture if attacked, so leading to greater direct mortality rates. 
It is important to point out that demonstrating relatively strong lethal effects compared to another species does not mean that non-lethal effects are not important for the most preferred species, just that it is likely that the preferred species will show higher levels of direct mortality relative to less vulnerable species (all other things being equal). And of course, this means that non-lethal effects may be relatively much larger in non-preferred species, particularly when it is behavioural compensation which determines whether a prey species is preferred.

A similar situation of greater expected lethal effects on bird populations for most preferred prey might also apply to situations where predators have limited prey choice, for example, more linear trophic chains where the predator eats mostly one species of prey such as the Hen Harrier Circus cyaneus, Red Grouse Lagopus lagopus, and Meadow Pipit Anthus pratensis system (Redpath 1991; Redpath et al. 2001). If predators have no choice, then investment by prey in anti-predation behaviour will not affect the number of prey killed, assuming a stable predator population. But again this does not mean non-lethal effects are not important, and indeed intra-specific competition amongst the prey may lead to very strong non-lethal effects. It is likely that many classic cases of "top down" control where predators have been shown to affect prey populations through lethal effects are probably driven by nonlethal effects that were acting in the same direction as the expected lethal effects (Peckarsky et al. 2008).

\section{Evolutionary or cultural lag and constraints on non-lethal compensation}

Strong lethal effects on prey populations are often noted when non-native predators are introduced into communities where a functionally equivalent predator species has been absent in evolutionary time (Innes et al. 2010). Alien predators are also tend to cause larger lethal effects than native predators (Salo et al. 2007) and this may be because bird species long isolated from predators frequently lack appropriate responses when exposed to newly introduced predators. Many native New Zealand bird species, for example, have declined because they lack flight or the behaviours to compensate non-lethally to mammalian predators which were completely absent on these islands until the last few centuries (Innes et al. 2010). 
Particularly extreme strong lethal effects can arise because bird species lack the physical ability to make non-lethal avoidance responses: flightlessness constrains avoidance responses that allow nearly all bird species to ignore many potential predators (Pomeroy 1990). This illustrates the continuum of non-lethal effects influencing individual behavioural decisions within species and between species through to life history evolution and even the evolution of the class characteristics of birds. Flight generally in birds can be considered a very large non-lethal effect. The physiological mechanisms and energy required for flight involve considerable costs (Videler 2005) but allow birds generally to avoid many predators. When predators are absent, as has occurred hundreds of times on oceanic islands, birds may rapidly become flightless, because bearing the costs of flight then leads to a selective disadvantage (see Steadman 1995).

Strong lethal effects from introduced predators may arise more typically because of responseto-predator naiveté (Sih et al. 2010). Species may lack anti-predation behaviours that have a genetic basis, or lack the cultural information to respond to the new predator appropriately. If selection does not have sufficient time to operate, or the cultural innovation to respond appropriately does not arise and spread sufficiently quickly, then species can be driven to extinction - the ultimate lethal effect. The lack of behavioural response may be more subtle than the examples described above. Nesting on the ground or conspicuously or lack of fleeing responses to predators or vigilance (e.g. Blumstein and Daniel 2005) could also result in large direct lethal effects. It is important to note that any population declines from introduced predators are likely to involve prey showing inappropriate non-lethal effects, which reduce fitness (Sih et al. 2010): these would generally act in the same direction as lethal effects and might well be as overlooked as have non-lethal effects in many classic top-down control case studies (see Peckarsky et al. 2008).

Strong lethal effects on bird populations are also observed for introduced predators in continental areas (Salo et al. 2007). The same principles apply as on islands but the effects of the introduced predators' interactions with pre-existing indigenous predators, and the existing potential for non-lethal responses that are present because of the indigenous predators, 
makes predictions about the relative strength of lethal and non-lethal effects more difficult (Letnic et al. 2009). It seems likely that introduced predators that have a functionally indigenous equivalent will exert lower lethal effects on their prey, though prey populations may decline because they have to make a greater level of non-lethal response to the increased predator density. In reverse, there may well be situations where prey have well developed riskreduction behaviours to indigenous predators, that actually result in increased lethal effects for an introduced predator, because they are inappropriate for that predator that may have a particularly novel hunting behaviour, or habitat specialisation (e.g. Igual et al. 2007).

Another factor that may interact with introduced predators to lead to large direct lethal effects may be anthropogenic habitat change (Diamond 1989). It is well known that anthropogenic habitats may favour introduced species (Facon et al. 2006), but anthropogenic habitat change itself may further reduce the ability of prey to compensate non-lethally, leading to greater perceived population effects as predators can then exert stronger lethal effects. For example, habitat quality may affect Grey Partridges' Perdix perdix ability to forage effectively while still maintaining vigilance for Sparrowhawks (Watson et al. 2007). Declines in farmland birds in the UK generally may be partly linked to changes in habitat quality, so that bird species cannot effectively manage their predation risk (Evans 2004; Whittingham and Evans 2004). Reduction in habitat heterogeneity generally seems likely to increase the strength of lethal effects because it reduces the ability of animals to respond non-lethally (Trussell et al. 2006).

\section{Predator partnerships that exploit non-lethal compensation}

Predators hunt prey in diverse ways that are often species specific. Peregrines, for example, catch prey mainly in flight after a chase, whereas Sparrowhawks catch prey mainly on the ground or just as prey take flight without a chase (Cresswell 1996). This is shown spectacularly with Redshanks which will crouch on attack by Peregrines to reduce their risk of capture relative to flying, but will fly on attack by Peregrines to reduce their risk of capture from Sparrowhawks (Cresswell 1993). Peregrines may attack Redshanks from cover in low flights which resemble the characteristic attacks of Sparrowhawks and consequently Redshanks 
may fly inappropriately. Although there is no evidence in this system yet to show that Peregrines may deliberately exploit the anti-predation responses of Redshanks to Sparrowhawks, or even more tantalising, that Peregrines time their hunts to coincide with periods of Sparrowhawk hunting to promote the chance of errors in response, the general premise should apply. Partnering of predators under similar circumstances has certainly been recorded, for example, Hen Harriers and Merlins Falco columbarius (Bourne 1960). A diverse predator suite which hunts the same prey in different ways may prevent any anti-predation behaviours from being effective and so larger lethal effects might be expected under these circumstances (Kotler et al. 1992).

\section{Can predation ever be unimportant in prey population dynamics?}

To conclude, predation may be perceived to be unimportant in population dynamics because non-lethal effects (or density-dependent competition effects) have not been fully considered. Occasionally predation is actually unimportant in population dynamics because of special circumstances such as escape from predators either spatially or because of predators choose more vulnerable prey.

Despite exceptions, predation will almost always be an important component to population dynamics because it always constrains access to resources and so will always affect levels of intra-specific competition. But availability of resources itself also determines the effects of predation. Behavioural compensation to predation risk depends on the level of resources in the environment to offset these costs. As costs rise and/or resource levels fall so lethal effects become dominant. As costs fall and/or resource levels rise so non-lethal effects occur. Prey population dynamics therefore arises from the interaction of predation risk and resource levels changing the amount of intra-specific competition. Even in the case of compensatory mortality, individuals that would never have bred that might be part of the potential "doomed surplus" killed by predators, affect those surviving individuals through changes in intraspecific competition. Overall, predator presence or absence may not affect the year to year level of a breeding population of birds within a defined area and so may be viewed as being relatively 
unimportant in limiting the prey population. In practical terms, whether for management for harvest, or conservation, then predators are not affecting the headline bird population. But the timing and causes of mortality may still be strongly affected by the predator because of inevitable changes in levels of intraspecific and interspecific competition, and their knock on community effects. If predators are removed completely, the competitive composition of the prey population and how it uses space and resources will always change (Boyce et al. 1999).

In other words, predators always change local population density and so competition for resources (Boyce et al. 1999; Chase et al. 2002). This is particularly so in animals which have the capacity to show compensatory anti-predation behaviour (Preisser et al. 2005). Birds, of course, are complex vertebrates with well-developed physical, cognitive and learning capabilities so that they can respond rapidly and effectively to risk, over large spatial and temporal scales (Lima and Dill 1990; Lima 1993; Caro 2005). Therefore bird populations are perhaps the most likely to show the effects of predation on population dynamics, and these effects will be manifest mainly through non-lethal effects.

For a study to conclude that predators do not significantly affect prey populations (for a defined spatial and temporal scale) it must demonstrate that:

1. Lethal effects do not significantly change the density of prey, such that the level of intraspecific competition in the prey is not significantly affected.

2. The costs of non-lethal compensation by the prey to the predator do not significantly change the level of intraspecific competition in the prey.

Temporal and spatial scale is important because as argued above, predation is almost certain to affect density-dependent competitive processes within a prey population at some scale (Boyce et al. 1999; Chase et al. 2002). Like many ecological processes, it is actually defining the scale of when or where predation affects prey populations, and the circumstances under which it occurs, that are the key questions, not simply whether predation has effects or not. 


\section{Acknowledgements}

I thank Franz Barlein for inviting me to take part in the symposium to celebrate the $100^{\text {th }}$

anniversary of IFV. I thank lan Newton, Peter Becker and an anonymous referee for helpful comments on an earlier draft. 


\section{References}

Abrams PA (1984) Foraging time optimization and interactions in food webs. Am. Nat. 124: 80-96

Abrams PA (1991) Strengths of indirect effects generated by optimal foraging. Oikos 62: $167-$ 176

Abrams PA (1993) Why predation rate should not be proportional to predator density. Ecology 74: $726-733$

Agrawal AA (2001) Phenotypic plasticity in the interactions and evolution of species. Science 294: $321-326$

Amar A, Redpath S, Sim I, Buchanan G (2010) Spatial and temporal associations between recovering populations of common raven Corvus corax and British upland wader populations. J. Appl. Ecol. 47: 253-262

Backman J, Alerstam T (2001) Confronting the winds: orientation and flight behaviour of roosting swifts, Apus apus. P. Roy. Soc. Lond. B Bio. 268: 1081-1087

Balaz M, Weidinger K, Kocian L, Nemethova D (2007) Effect of habitat on blackcap, Sylvia atricapilla nest predation in the absence of corvid predators. Fol. Zool. 56: 177-185

Bennett PM, Owens IPF (2002) Evolutionary Ecology of Birds: Life Histories, Mating Systems and Extinction. Oxford University Press, Oxford

Blumstein DT, Daniel JC (2005) The loss of anti-predator behaviour following isolation on islands. P. Roy. Soc. Lond. B Bio. 272: 1663-1668 
Bolker B, Holyoak M, Krivan V, Rowe L, Schmitz O (2003) Connecting theoretical and empirical studies of trait-mediated interactions. Ecology 84: 1101-1114

Bolnick DI, Preisser EL (2005) Resource competition modifies the strength of trait-mediated predator-prey interactions: A meta-analysis. Ecology 86: 2771-2779

Bolton M, Tyler G, Smith K, Bamford R (2007) The impact of predator control on lapwing Vanellus vanellus breeding success on wet grassland nature reserves. J. Appl. Ecol. 44: 534544

Bourne WRP (1960) A hunting partnership between two birds of prey. Ibis 102: 136

Boyce MS, Sinclair ARE, White GC (1999) Seasonal compensation of predation and harvesting. Oikos 87: 419-426

Brown JS, Kotler BP (2004) Hazardous duty pay and the foraging cost of predation. Ecol. Letts. 7: 999-1014

Brown JS, Laundre JW, Gurung M (1999) The ecology of fear: Optimal foraging, game theory, and trophic interactions. J. Mammal. 80: 385-399

Butler SJ, Whittingham MJ, Quinn JL, Cresswell W (2005) Quantifying the interaction between food density and habitat structure in determining patch selection. Anim. Behav. 69: 337-343

Caro TM (2005) Antipredator defenses in birds and mammals. University of Chicago Press, Chicago

Chase JM, Abrams PA, Grover JP, Diehl S, Chesson P, Holt RD, Richards SA, Nisbet RM, Case TJ (2002) The interaction between predation and competition: a review and synthesis. Ecol. Letts. 5: 302-315 
Creel S, Christianson D (2008) Relationships between direct predation and risk effects.

Trends Ecol. Evol. 23: 194-201

Cresswell W (1993) Escape responses by redshanks, Tringa totanus, on attack by avian predators. Anim. Behav. 46: 609-611

Cresswell W (1994) Age-dependent choice of redshank (Tringa totanus) feeding location: profitability or risk? J. Anim. Ecol. 63: 589-600

Cresswell W (1995) Selection of avian prey by wintering sparrowhawks Accipiter nisus in southern Scotland. Ardea 83: 381-389

Cresswell W (1996) Surprise as a winter hunting strategy in Sparrowhawks Accipiter nisus, Peregrines Falco peregrinus and Merlins F. columbarius Ibis 138: 684-692

Cresswell W (2008) Non-lethal effects of predation risk in birds Ibis 150 3-17

Cresswell W, Holt S, Reid JM, Whitfield DP, Mellanby RJ, Norton DW, Waldron S (2004) The energetic costs of egg heating constrain incubation attendance but do not determine daily energy expenditure in the pectoral sandpiper. Behav. Ecol. 15: 498-507

Cresswell W, Lind J, Quinn JL (2010) Predator hunting success and prey vulnerability: quantifying the spatial scale over which lethal and non-lethal effects of predation occur. J. Anim. Ecol. 79: 556-562

Cresswell W, Whitfield DP (1994) The effects of raptor predation on wintering wader populations at the Tyninghame estuary, southeast Scotland. Ibis 136: 223-232

Cresswell W, Whitfield DP (2008) How starvation risk in Redshanks results in predation mortality from Sparrowhawks. Ibis 150: 209-218 
Crooks KR, Soule ME (1999) Mesopredator release and avifaunal extinctions in a fragmented system. Nature $400: 563-566$

Dekker D (1998) Over-ocean flocking by Dunlins, Calidris alpina, and the effect of raptor predation at Boundary Bay, British Columbia. Can. Field Nat. 112: 694-697

Diamond JM (1989) The present, past and future of human-caused extinctions. Philos. T. Roy. Soc. B 325: 469-477

Dobson A, Power DM (1990) Survival rates and their relationship to life-history traits in some common British Birds. Curr. Ornith. 7: 115-146

Dunnet GM, Ollason JC (1978) The Estimation of Survival Rate in the Fulmar, Fulmarus glacialis. J. Anim. Ecol. 47: 507-520

Duriez O, Fritz H, Binet F, Tremblay $Y$, Ferrand $Y(2005)$ Individual activity rates in wintering Eurasian woodcocks: starvation versus predation risk trade-off? Anim. Behav. 69: 39-49

Errington PL (1943) An analysis of mink predation upon muskrats in north-central United States. lowa Ag. Res. Bull. 320: 798-924

Errington PL (1945) Some contributions of a fifteen-year study of the northern bobwhite to a knowledge of population phenomena. Ecol. Monog. 15: 1-34

Evans KL (2004) The potential for interactions between predation and habitat change to cause population declines of farmland birds. Ibis 146: 1-13

Facon B, Genton BJ, Shykoff J, Jarne P, Estoup A, David P (2006) A general eco-evolutionary framework for understanding bioinvasions. Trends Ecol. Evol. 21: 130-135 
Fletcher K, Aebischer NJ, Baines D, Foster R, Hoodless AN (2010) Changes in breeding success and abundance of ground-nesting moorland birds in relation to the experimental deployment of legal predator control. J. Appl. Ecol. 47: 263-272

Fontaine JJ, Martel M, Markland HA, Niklison AA, Decker KL, Martin TE (2007) Testing ecological and behavioral correlates of nest predation. Oikos 116: 1887-1894

Gosler AG (1996) Environmental and social determinants of winter fat storage in the great tit Parus major J. Anim. Ecol. 65: 1-17

Götmark F, Post P (1996) Prey selection by Sparrowhawks, Accipiter nisus - relative predation risk for breeding passerine birds in relation to their size, ecology and behavior. Philos. T. Roy. Soc. B 351: 1559-1577

Grand TC (2002) Alternative forms of competition and predation dramatically affect habitat selection under foraging-predation-risk trade-offs. Behav. Ecol. 13: 280-290

Green RE, Tyler GA, Stowe TJ, Newton AV (1997) A simulation model of the effect of mowing of agricultural grassland on the breeding success of the corncrake (Crex crex). J. Zool. 243: $81-115$

Hagelin JC (2003) A field study of ornaments, body size, and mating behavior of the Gambel's Quail. Wilson Bull. 115: 246-257

Hanssen SA, Engebretsen H, Erikstad KE (2002) Incubation start and egg size in relation to body reserves in the common eider. Behav. Ecol. Sociobiol. 52: 282-288

Heithaus MR, Wirsing AJ, Burkholder D, Thomson J, Dill LM (2009) Towards a predictive framework for predator risk effects: the interaction of landscape features and prey escape tactics. J. Anim. Ecol. 78: 556-562 
Holt RH, Davies ZG, Staddon S (2008) Meta-Analysis of the Effects of Predation on Animal Prey Abundance: Evidence from UK Vertebrates. PLoS ONE 3(6): e2400:

doi:10.1371/journal.pone. 0002400

Houston AI, McNamara JM, Hutchinson JMC (1993) General results concerning the trade-off between gaining energy and avoiding predation. Philos. T. Roy. Soc. B 341: 375-397

Igual JM, Forero MG, Gomez T, Oro D (2007) Can an introduced predator trigger an evolutionary trap in a colonial seabird? Biol. Cons. 137: 189-196

Inger R, Bearhop S, Robinson JA, Ruxton G (2006) Prey choice affects the trade-off balance between predation and starvation in an avian herbivore. Anim. Behav. 71: 1335-1341

Inger R, Gudmundsson GA, Ruxton GD, Newton J, Colhoun K, Auhage S, Bearhop S (2008) Habitat utilisation during staging affects body condition in a long distance migrant, Branta bernicla hrota: potential impacts on fitness? J. Av. Biol. 39: 704-708

Innes J, Kelly D, Overton JM, Gillies C (2010) Predation and other factors currently limiting New Zealand forest birds. New Zeal. J. Ecol. 34: 86-114

Jenkins D, Watson A, Miller GR (1964) Predation and Red Grouse populations. J. Appl. Ecol. 1: $183-195$

Kotler BP, Blaustein L (1995) Titrating food and safety in a heterogeneous environment - when are the risky and safe patches of equal value. Oikos 74: 251-258

Kotler BP, Blaustein L, Brown JS (1992) Predator facilitation - the combined effect of snakes and owls on the foraging behavior of gerbils. Ann. Zool. Fenn. 29: 199-206

Krebs CJ, Boutin S, Boonstra R, Sinclair ARE, Smith JNM, Dale MRT, Martin K, Turkington R (1995) Impact of Food and Predation on the Snowshoe Hare Cycle. Science 269: 1112-1115 
Krivan V, Schmitz OJ (2004) Trait and density mediated indirect interactions in simple food webs. Oikos 107: 239-250

Lack D (1954) The natural regulation of animal numbers. Clarendon, Oxford

Lack D (1956) Swifts in a tower. Methuen, London

Lank DB, Butler RW, Ireland J, Ydenberg RC (2003) Effects of predation danger on migration strategies of sandpipers. Oikos 103: 303-319

Larsen T, Sordahl TA, Byrkjedal I (1996) Factors related to aggressive nest protection behaviour: A comparative study of Holarctic waders. Biol. J. Linn. Soc. 58: 409-439

Lecomte VJ, Sorci G, Cornet S, Jaeger A, Faivre B, Arnoux E, Gaillard M, Trouve C, Besson D, Chastel O, Weimerskirch $\mathrm{H}$ (2010) Patterns of aging in the long-lived wandering albatross. P. Natl. Acad. Sci. USA 107: 6370-6375

Leibold M (1991) Trophic interactions and habitat segregation between competing Daphnia species. Oecologia 86: 510-520

Lessells CM, Krebs JR, Davies NB (1991). The evolution of life histories. In Behavioural Ecology:An Evolutionary Approach. pp. 137-168. Blackwell Scientific Publications, Oxford

Letnic M, Koch F, Gordon C, Crowther MS, Dickman CR (2009) Keystone effects of an alien top-predator stem extinctions of native mammals. P. Roy. Soc. Lond. B Bio. 276: 3249-3256

Lima SL (1986) Predation risk and unpredictable feeding conditions: determinants of body mass in birds. Ecology 67: 377-385

Lima SL (1993) Ecological and evolutionary perspectives on escape from predatory attack - a survey of North-American birds. Wilson Bull. 105: 1-47 
Lima SL (1998) Nonlethal effects in the ecology of predator-prey interactions - What are the ecological effects of anti-predator decision-making? Bioscience 48: 25-34

Lima SL (2002) Putting predators back into behavioral predator-prey interactions. Trends Ecol. Evol. 17: 70-75

Lima SL (2009) Predators and the breeding bird: behavioral and reproductive flexibility under the risk of predation. Biol. Rev. 84: 485-513

Lima SL, Dill LM (1990) Behavioural decisions made under the risk of predation: a review and prospectus. Can. J. Zool. 68: 619-640

Lima SL, Mitchell WA, Roth TC (2003) Predators feeding on behaviourally responsive prey: some implications for classical models of optimal diet choice. Evol. Ecol. Res. 5: 1083-1102

Lingle S, Pellis SM, Wilson WF (2005) Interspecific variation in antipredator behaviour leads to differential vulnerability of mule deer and white-tailed deer fawns early in life. J. Anim. Ecol. 74: $1140-1149$

Luttbeg B, Kerby JL (2005) Are scared prey as good as dead? Trends Ecol. Evol. 20: 416-418

Luttbeg B, Rowe L, Mangel M (2003) Prey state and experimental design affect relative size of trait- and density-mediated indirect effects. Ecology 84: 1140-1150

MacLeod R, Barnett P, Clark JA, Cresswell W (2005) Body mass change strategies in blackbirds Turdus merula : the starvation-predation risk trade-off. J. Anim. Ecol. 74: 292-302

Macleod R, Clark J, Cresswell W (2008) The starvation-predation risk trade-off, body mass and population status in the Common Starling Sturnus vulgaris. Ibis 150: 199-208 
Martin TE (1991) Food limitation in terrestrial breeding bird populations: is that all there is? P. 20th Int. Ornith. Cong. 20: 1595-1602

McGowan A, Cresswell W, Ruxton GD (2002) The effects of daily weather variation on foraging and responsiveness to disturbance in overwintering Red Knot (Calidris canutus). Ardea 90: 229-237

McNamara JM, Houston Al (1987) Starvation and predation as factors limiting population size. Ecology 68: 1515-1519

McNamara JM, Houston Al, Lima SL (1994) Foraging routines of small birds in winter: A theoretical investigation. J. Av. Biol. 25: 287-302

Milinski M, Heller R (1978) The influence of a predator on optimal foraging behaviour of sticklebacks ( Gasterosteus aculeatus L. ). Nature 275: 642-644

Newson SE, Rexstad EA, Baillie SR, Buckland ST, Aebischer NJ (2010) Population change of avian predators and grey squirrels in England: is there evidence for an impact on avian prey populations? J. Appl. Ecol. 47: 244-252

Newton I (1986) The Sparrowhawk. Poyser, Calton

Newton I (1993) Predation and limitation of bird numbers. Curr. Ornith. 11: 143-198

Newton I (1998) Population limitation in birds. Academic Press, London

Paclik M, Misik J, Weidinger K (2009) Nest predation and nest defence in European and North American woodpeckers: a review. Ann. Zool. Fenn. 46: 361-379

Page G, Whitacre DF (1975) Raptor predation on wintering shorebirds. Condor 77: 73-83 
Partridge L, Barton NH (1993) Optimality, mutation and the evolution of aging. Nature 362 : $305-311$

Partridge L, Harvey PH (1988) The ecological context of life history evolution. Science 24: $1449-1455$

Peckarsky BL, Abrams PA, Bolnick DI, Dill LM, Grabowski JH, Luttbeg B, Orrock JL, Peacor SD, Preisser EL, Schmitz OJ, Trussell GC (2008) Revisiting the classics: Considering nonconsumptive effects in textbook examples of predator-prey interactions. Ecology 89: 24162425

Peckarsky BL, McIntosh AR (1998) Fitness and community consequences of avoiding multiple predators. Oecologia 113: 565-576

Perez-Tris J, de la Puente J, Pinilla J, Bermejo A (2001) Body moult and autumn migration in the barn swallow Hirundo rustica: is there a cost of moulting late? Ann. Zool. Fenn. 38: 139148

Perrins CM, Geer TA (1980) The effect of sparrowhawks on tit populations. Ardea 68: 133-142

Pomeroy D (1990) Why fly? The possible benefits for lower mortality. Biol. J. Linn. Soc. 40: 53-65

Pravosudov VV, Grubb TC, Nolan Jr V, Ketterson ED, Thompson CF (1997) Energy management in passerine birds during the nonbreeding season. Curr. Ornith. 14: 189-234

Preisser EL, Bolnick DI, Benard MF (2005) Scared to death? The effects of intimidation and consumption in predator-prey interactions. Ecology 86: 501-509

Preisser EL, Bolnick DI, Grabowski JH (2009) Resource dynamics influence the strength of non-consumptive predator effects on prey. Ecol. Letts. 12: 315-323 
Puigcerver M, Gallego S, Rodriguezteijeiro ID, J.C. S (1992) Survival and mean life span of the quail Coturnic c. coturnix. Bird Study 39: 120-123

Redpath SM (1991) The impact of hen harriers on red grouse breeding success. J. Appl. Ecol. 28: $659-671$

Redpath SM, Thirgood SJ, Leckie F (2001) Does supplementary feeding reduce predation of red grouse by hen harriers? J. Appl. Ecol. 38: 1157-1168

Ritchie EG, Johnson CN (2009) Predator interactions, mesopredator release and biodiversity conservation. Ecol. Letts. 12: 982-998

Roth TC, Lima SL, Vetter WE (2006) Determinants of predation risk in small wintering birds: the hawk's perspective. Behav. Ecol. Sociobiol. 60: 195-204

Salo P, Korpimaki E, Banks PB, Nordstrom M, Dickman CR (2007) Alien predators are more dangerous than native predators to prey populations. P. Roy. Soc. Lond. B Bio. 274: 12371243

Schmidt-Wellenburg CA, Visser GH, Biebach B, Delhey K, Oltrogge M, Wittenzellner A, Biebach H, Kempenaers B (2008) Trade-off between migration and reproduction: does a high workload affect body condition and reproductive state? Behav. Ecol. 19: 1351-1360

Schmitz OJ, Krivan V, Ovadia O (2004) Trophic cascades: the primacy of trait-mediated indirect interactions. Ecol. Letts. 7: 153-163

Selas V (1993) Selection of prey by breeding Sparrowhawks Accipiter nisus in southern Norway: the importance of size and foraging behaviour of prey. Ornis Fenn. 70: 144-154

Sergio F, Hiraldo F (2008) Intraguild predation in raptor assemblages: a review. Ibis 150: $132-$ 145 
Sih A (1980) Optimal behaviour: can foragers balance two conflicting demands. Science 210: $1041-1043$

Sih A (1982) Foraging strategies and the avoidance of predation by an aquatic insect Notonecta hoffmanni. Ecology 63: 786-796

Sih A (1987) Prey refuges and predator-prey stability. Theor. Pop. Biol. 31: 1-12

Sih A, Bolnick DI, Luttbeg B, Orrock JL, Peacor SD, Pintor LM, Preisser E, Rehage JS, Vonesh JR (2010) Predator-prey naivete, antipredator behavior, and the ecology of predator invasions. Oikos 119: 610-621

Sih A, Christensen B (2001) Optimal diet theory: when does it work, and when and why does it fail? Anim. Behav. 61: 379-390

Smith RK, Pullin AS, Stewart GB, Sutherland WJ (2010) Effectiveness of Predator Removal for Enhancing Bird Populations. Cons. Biol. 24: 820-829

Steadman DW (1995) Prehistoric extinction of Pacific island birds - biodiversity meets zooarchaeology. Science 267: 1123-1131

Stillman RA, Goss-Custard JD (2002) Seasonal changes in the response of oystercatchers Haematopus ostralegus to human disturbance. J. Av. Biol. 33: 358-365

Tharme AP, Green RE, Baines D, Bainbridge IP, O'Brien M (2001) The effect of management for red grouse shooting on the population density of breeding birds on heather-dominated moorland. J. Appl. Ecol. 38: 439-457

Tinbergen L (1946) Sperver als Roofvijand zan Zangvogels. Ardea 34: 1-123 
Tornberg R (1997) Prey selection of the goshawk Accipiter gentilis during the breeding season: the role of prey profitability and vulnerability. Ornis Fenn. 74: 15-28

Trussell GC, Ewanchuk PJ, Matassa CM (2006) Habitat effects on the relative importance of trait- and density-mediated indirect interactions. Ecol. Letts. 9: 1245-1252

Tschanz B, Bersier LF, Bacher S (2007) Functional responses: A question of alternative prey and predator density. Ecology 88: 1300-1308

van der Veen IT (2000) Daily routines and predator encounters in Yellowhammers Emberiza citrinella in the field during winter. Ibis 142: 413-420

Videler JJ (2005) Avian Flight. Oxford University Press, Oxford

Watson M, Aebischer NJ, Cresswell W (2007) Vigilance and fitness in grey partridges Perdix perdix : the effects of group size and foraging-vigilance trade-offs on predation mortality. J. Anim. Ecol. 76: 211-221

Whittingham MJ, Evans KL (2004) The effects of habitat structure on predation risk in birds in agricultural landscapes. Ibis 146 suppl. 2: 210-220

Wirsing AJ, Cameron KE, Heithaus MR (2010) Spatial responses to predators vary with prey escape mode. Anim. Behav. 79: 531-537

Yasue M, Quinn JL, Cresswell W (2003) Multiple effects of weather on the starvation and predation risk trade-off in choice of feeding location in redshanks. Func. Ecol. 17: 727-736

Ydenberg RC, Butler RW, Lank DB, Smith BD, Ireland J (2004) Western sandpipers have altered migration tactics as peregrine falcon populations have recovered. P. Roy. Soc. Lond. B Bio. 271: 1263-1269 
Zanette L, Clinchy M, Smith JNM (2006) Combined food and predator effects on songbird nest survival and annual reproductive success: results from a bi-factorial experiment. Oecologia 147: $632-640$

Zanette L, Smith JNM, van Oort H, Clinchy M (2003) Synergistic effects of food and predators on annual reproductive success in song sparrows. P. Roy. Soc. Lond. B Bio. 270: 799-803 


\section{Figure Legends}

Fig. 1: The concept of lethal and non-lethal space. (A.) In the presence of a predator some resources are only available at high risk of direct predation mortality (hence lethal effects and lethal space), but as long as animals remain in non-lethal space they survive, but at a potential cost of not using lethal space. (B.) When the predator is not present, animal populations can expand because lethal space becomes non-lethal space and so available. (C.) If resource levels decrease, so non-lethal space decreases and so population size decreases as animals are forced into lethal space. The smaller graphs to the left of each of the three diagrams show the resulting change in population size.

Fig. 2: How lethal effects arise as a consequence of resource availability. The figure is also an illustration of the starvation-predation risk trade-off. Below a threshold availability of resources (the dotted line) some proportion of the population start to occupy lethal space (or a percentage of resources allocated to anti-predation behaviour must be reallocated to combat starvation) and so there is an increase in predation risk and so direct mortality.

Fig. 3: How experimental changes in resource level can lead to both no population changes and population changes in prey populations. Below a threshold availability of resources (the dotted line, see also Fig. 2, where some proportion of the population start to occupy lethal space), experimental addition of resources will reduce mortality (direct predation effects) because individuals can move above the threshold. Experimental addition of resources above the threshold will not change mortality (direct predation effects) because all individuals already have sufficient resources to minimise predation risk. 
Fig. 1:
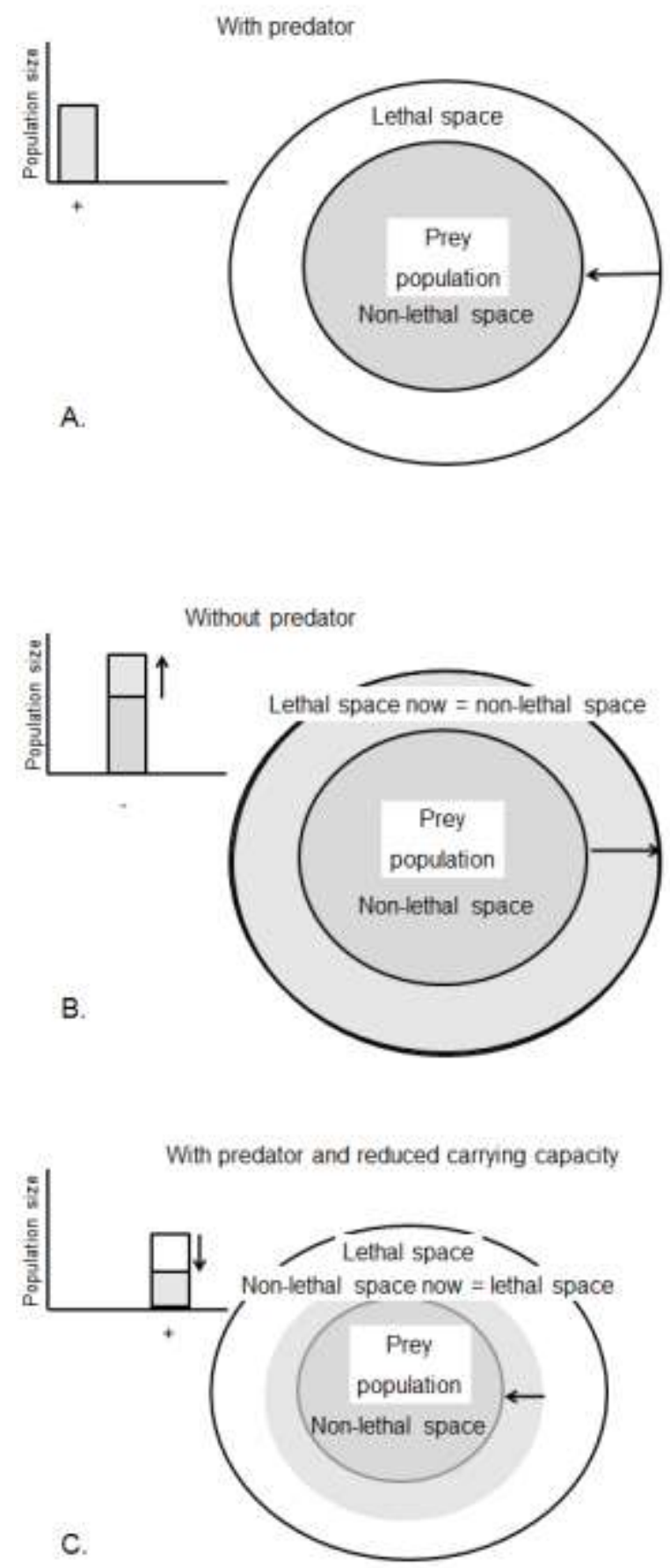
Fig. 2:

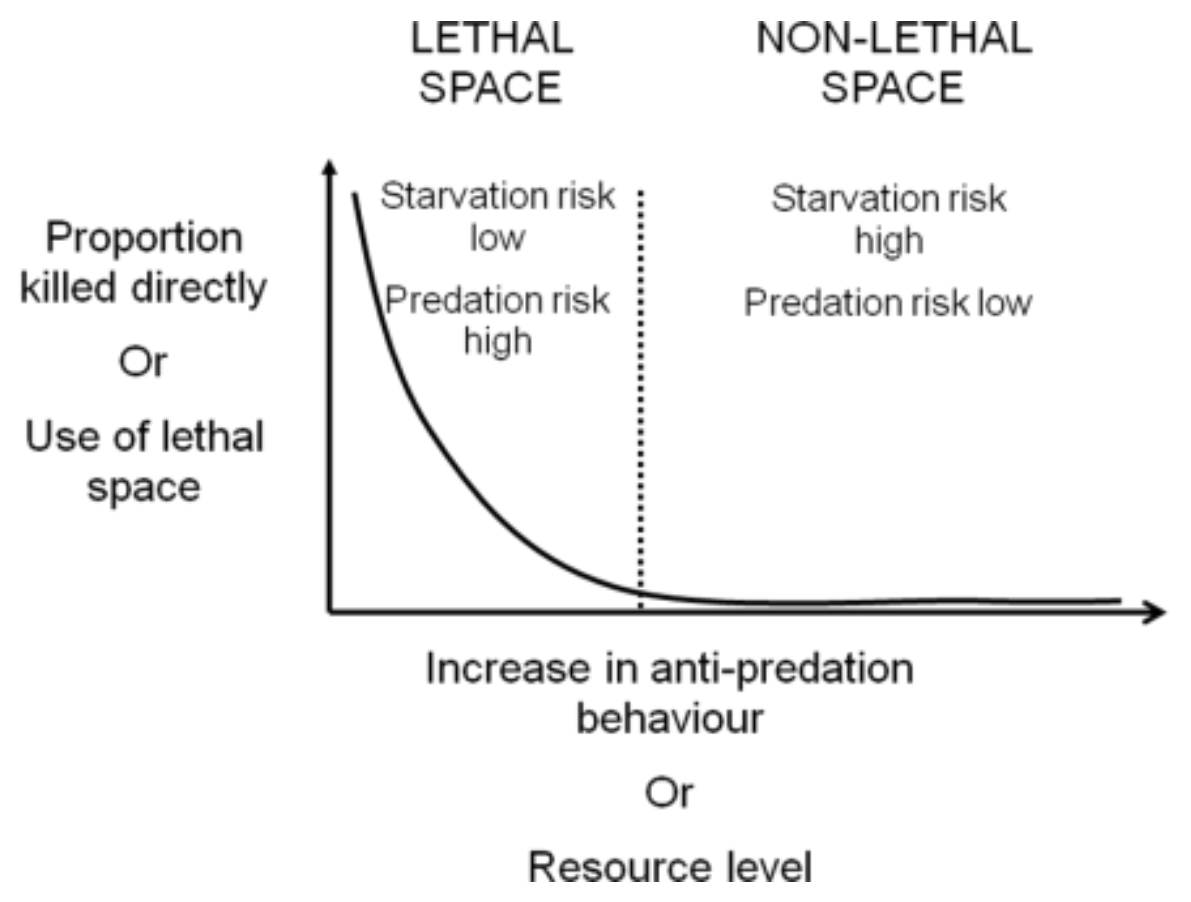


Fig. 3:

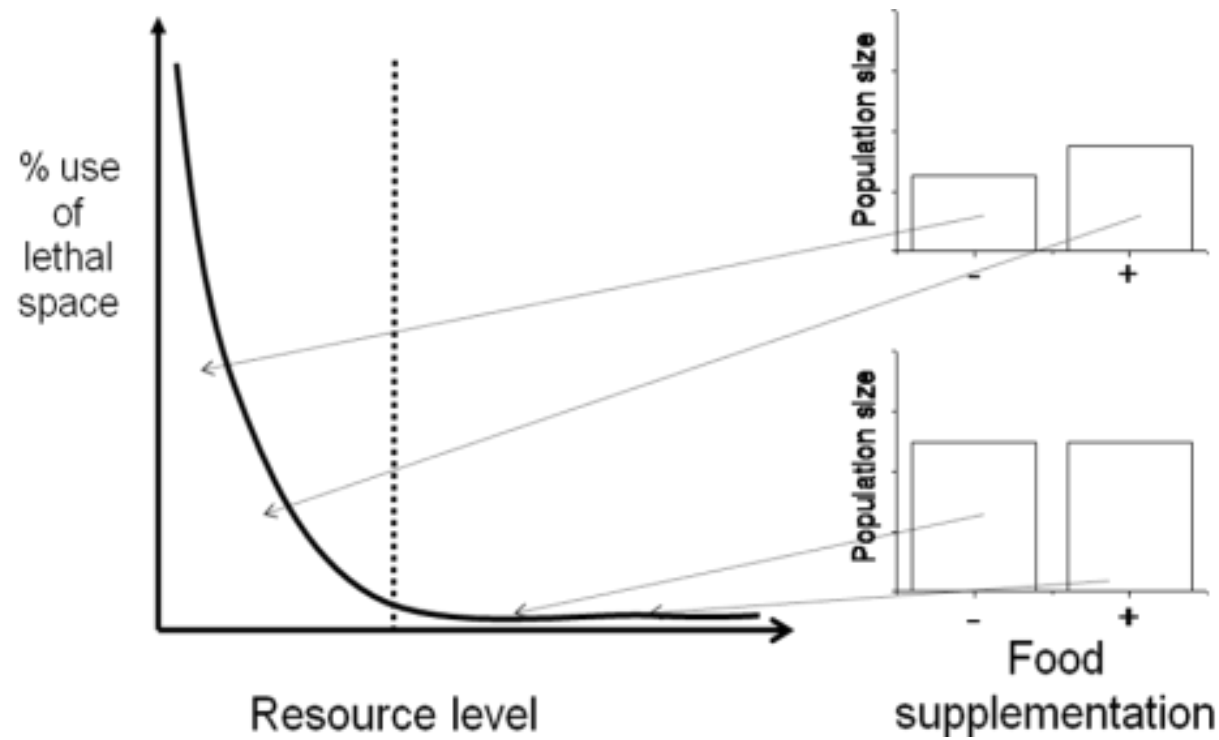

